\title{
Entrevista
}

\section{A Idade Média foi instaurada no Brasil?}

Eduardo Soczek Mendes ${ }^{1}$

\section{Resumo}

Entrevista realizada, no dia 08 de setembro de 2019, com a medievalista, Prof. ${ }^{\text {a Dr. }}$. Marcella Lopes Guimarães, do Departamento de História e do Programa de Pós-graduação em História da Universidade Federal do Paraná. Foram abordados temas que interessam à pesquisa da professora e também a apropriação inadequada do termo "Idade Média" para a definição de retrocessos. Gentilmente, a Professora nos respondeu sobre as temáticas do Brasil contemporâneo e acerca do papel do investigador medievalista em nosso país.

\section{Palavras-chave}

Medievo. Brasil. Definições.

\begin{abstract}
Interview held on September 8, 2019, with the medievalist, Prof. Dr. Marcella Lopes Guimarães, from the Department of History and the Graduate Program in History of the Federal University of Paraná. Topics that concern the professor's research were addressed, as well as the inappropriate appropriation of the term "Middle Ages" for the definition of setbacks. Kindly, the professor answered us regarding the themes of contemporary Brazil and the role of the medievalist researcher in our country.
\end{abstract}

\section{Keywords}

Medieval. Brazil. Definitions.

1 Professor de Literatura Portuguesa e Teoria da Literatura, com vínculo de colaborador, filiado ao Departamento de Letras da Universidade Estadual do Centro-Oeste (Santa Cruz, Guarapuava, Paraná). E-mail: edu.soczek@gmail.com. 
As correntes associações entre a Idade Média e o atraso ou o retrocesso não são nada adequadas. E isso nos explica a medievalista, Marcella Lopes Guimarães, Professora do Departamento de História e coordenadora do Programa da PósGraduação em História da Universidade Federal do Paraná. Gentilmente, a pesquisadora aceitou o nosso convite para discorrer sobre a relação que se faz entre o medievo e os acontecimentos estarrecedores no Brasil - elogios a notórios torturadores, cortes na Educação, o privilégio de algumas igrejas em um Estado Laico e a censura de obras literárias, por exemplo. Marcella Lopes Guimarães possui graduação e mestrado em Letras pela UFRJ e doutorou-se em História pela UFPR. Em 2014, atuou como Professora Visitante na Universidade de Poitiers, em França, e, em 2015, conquistou o III Prêmio UFES de Literatura, na categoria Livro de Literatura Infantil. Sim! A nossa entrevistada também escreve ficção, entre uma banca, uma orientação e a correria (ela também corre em maratonas!) da vida.

(autor): A sua formação inicial, pela UFRJ, foi Letras: graduação e o Mestrado, orientado pela $\operatorname{Prof}^{\mathrm{a}} \mathrm{Dr}^{\mathrm{a}}$. Teresa Cristina Cerdeira da Silva, uma das pioneiras nos estudos saramaguianos no Brasil. Depois, foi orientada, no Doutorado em História, pela Prof ${ }^{\mathrm{a}}$ Dr$^{\mathrm{a}}$. Fátima Frighetto, na UFPR. Quando surgiu o seu interesse pelo estudo da História? E pergunto mais: como a sua formação em Letras e o seu conhecimento em Literatura, por exemplo, a auxiliaram em suas pesquisas na área da História?

Marcella Lopes Guimarães: As disciplinas de Literatura Portuguesa e Fundamentos literários ibéricos que cursei na UFRJ propunham muitas leituras da área de História, sobretudo História de Portugal. Nós tínhamos de fato oportunidade de construir um conhecimento bastante satisfatório de contexto histórico. Esse conhecimento me fascinou e me aproximou de iniciativas interdisciplinares fora da UFRJ. Por exemplo, fiz vários cursos no Real Gabinete Português de Leitura. Eram cursos baratíssimos e extraordinários! Neles, conheci novelas de cavalaria e grandes especialistas. Entretanto, foi no Mestrado que entrevi a possibilidade de mudar de área, pela imersão na obra do cronista português Fernão Lopes. O Programa de Pós tinha conseguido trazer o Professor Helder Macedo do King's College como professor visitante e, na ocasião, ele nos apresentou o esboço do que haveria de ser o seu Viagens do olhar. Retrospecção, visão e profecia no Renascimento Português ${ }^{2}$. Eu conhecia

${ }^{2}$ Livro escrito com Fernando Gil (1937-2006), que foi professor de Filosofia na Universidade 
muito superficialmente a obra de Fernão Lopes (1385-1460) e, no Mestrado, durante a disciplina do Prof. Helder, li a Crônica de D. Pedro. Fiquei fascinada. Até hoje, tenho uma predileção por esse texto, que não tem a diversidade e o colorido da Crônica de D. João I, é claro, mas para mim pessoalmente e para as pesquisas que realizei depois, tornou-se um texto inesquecível.

Meu conhecimento de Literatura foi e é instrumental para a compreensão dos documentos na sua especificidade. Quando eu começo a trabalhar com uma narrativa, meu primeiro olhar é para seus elementos, suas metáforas, para a intertextualidade, para a sua poética.

(autor): A sua tese de Doutorado versa sobre o guarda-mor da Torre do Tombo e cronista-mor do reino de Portugal, Fernão Lopes. Obviamente, com as suas particularidades, Lopes foi financiado para escrever (e inscrever) as memórias pátrias por meio dos feitos dos reis. Como foi desenvolver no Brasil, um país tão jovem, um estudo sobre um cronista português da Idade Média?

M.L.G.: Os medievalistas brasileiros de minha geração, ou seja, que estão na casa dos 40 anos, têm sorte. Trabalhamos em um campo acadêmico consolidado. Gerações antes de nós construíram o campo e auferiram reconhecimento no país e no exterior. Os estudos medievais no Brasil são também um campo pujante e renovado. Por exemplo: acabo de fechar um dossiê na Revista Roda da Fortuna em que se destacam jovens medievalistas de expressão, que realizam pesquisas muito diversificadas. Mas a consolidação (que também se manifesta na vitória em editais, em bolsas $P Q$, por exemplo) não significa que se possa prescindir, dentro e fora da academia, da defensa do estudo das temporalidades mais recuadas.

(autor): Sabemos que a Idade Média compreende, oficialmente, um longuíssimo período, que vai da queda de Roma, em 476, à tomada de Constantinopla, em 1453. Isto é, são quase mil anos, e em mil anos muitas coisas acontecem. Por que a Idade Média ainda desperta tanta curiosidade nas pessoas e por que, na sua visão de especialista, há uma carga negativa com o termo "medieval", sendo que é comumente e metaforicamente associado com o atraso, a barbárie e o retrocesso?

de Lisboa e Diretor de Estudos na École de Hautes Études em Science sSociales de Paris. 
M.L.G.: Começo pela segunda parte da questão. A Idade Média, como modelo de compreensão de um tempo, nasceu "amaldiçoada"... Os humanistas que a inventaram, como tempo médio, época intermediária, compreenderamna como um longo intervalo que os afastava da idolatrada Antiguidade! Posteriormente, nos séculos XVII e XVIII, essa antipatia só se agudizou. O Romantismo reabilitou a Idade Média, mas, não devemos esquecer, à sua maneira, vinculando-a ao nascimento dos Estados Nacionais. Em geral, essa reabilitação foi boa para os estudos medievais? Para mim, foi! Muitos documentos foram editados no período e, em Portugal, nasceu um dos maiores historiadores românticos, por quem tenho imensa admiração, Alexandre Herculano, que percorreu com suas Lendas e Narrativas ${ }^{3}$ os velhos Livros de Linhagens medievais.

No mundo contemporâneo, um dos maiores colaboradores da atração que o medievo exerce sobre as pessoas é o cinema. Os filmes e séries são mesmo forjadores de imagens que temos do período, e muitos de nós fomos atraídos para o estudo dessa temporalidade pela nossa curiosidade de saber se "foi assim mesmo como se mostra nos filmes"! Pessoalmente, acho que mesmo um filme ruim - e meu julgamento passa longe de esperar que o cinema expresse a pesquisa histórica... - traz curiosidade que pode ser bem trabalhada pelos professores. Os cavaleiros, as disputas, as damas, as lendas, as revoltas, o amor cortês fascinam as pessoas - eu as compreendo bem, tudo isso me fascina! - e nos fascina tanto porque talvez reconheçamos falta de alguns valores que entrevemos naquele passado... Mas é preciso lembrar que filmes, séries, HQs, peças de teatro nos fornecem imagens que são mais ou muito menos (!) vinculadas à verdade. Quem acha que entendeu tudo de Idade Média, porque percorreu determinada série de sucesso com devoção está enganado.

(autor): Os retrocessos atuais no Brasil em relação à tentativa de cerceamento de liberdades artísticas e acadêmicas, por exemplo, podem ser associados metaforicamente com a Idade Média? E a perseguição às políticas de Direitos Humanos?

M.L.G.: Mais uma vez o poder das imagens... Muitos filmes insistem em nos apresentar um medievo dominado pela Igreja, por monarcas ferozes e em

\footnotetext{
${ }^{3}$ Alexandre Herculano (1810-1877) publicou diversos contos e novelas, a que chamou de primeiras tentativas de romance histórico em Língua Portuguesa, entre os anos de 1839 e 1844, nos periódicos O Panorama e A Ilustração. Em 1851, coligiu esses textos em tomos, intitulando-os Lendas e Narrativas (MENDES, 2017, p. 84).
} 
insistir no rótulo de "Idade das Trevas". O medievo foi muito luminoso, e obviamente que você, (autor), sabe que estou brincando com as Luzes, que, por sua vez, não tinham simpatia pela Idade Média... Construímos analogias com o medievo baseadas no nosso pouco ou raro conhecimento específico. $\mathrm{Na}$ verdade, nossos problemas e dificuldades de mantermos conquistas históricas (como os direitos humanos) são muito contemporâneos e deveríamos dar respostas contemporâneas a esses desafios.

(autor): Eu sei que é bastante complexo, mas, em linhas gerais, como é possível definir a "Idade Média" saindo dos clichês?

M.L.G.: A Idade Média é a tentativa de compreender uma temporalidade e é também um estudo. Trago uma definição muito clara, com a qual concordo na maior parte de seus elementos, formulada por Christian Amalvi (2006, p. 537):

A Idade Média não existe. Esse período de quase mil anos, que se estende da conquista da Gália por Clóvis [um historiador francês se expressando...] até o fim da Guerra dos Cem Anos, é uma fabricação, uma construção, um mito, quer dizer um conjunto de representações e de imagens em perpétuo movimento, amplamente difundidas na sociedade, de geração em geração.

Ninguém foi dormir na Idade Média e acordou na Época Moderna. Ideias, instituições "modernas" na verdade eram bem medievais..., daí Jacques Le Goff ter proposto uma longa Idade Média, avançando pela modernidade. Esses modelos, tentativas de compreensão, como Idade Média, Época Moderna, Contemporânea, são forjados na convicção mais ou menos amparada pela pesquisa de elementos comuns. Para mim, a Idade Média é também uma disciplina, um conhecimento sobre o passado.

(autor): As Sés Medievais são recheadas (e permita-me este uso do verbo) de gárgulas, que até podem ser consideradas obscenas em um templo. Talvez isso causaria arrepios no Brasil atual. Também muitos manuscritos contêm cantigas que satirizam o sagrado ou personagens do clero, além das próprias iluminuras. A Idade Média foi tão cerceadora com os artistas?

M.L.G.: Uma longa temporalidade e um grande perímetro cultural são abarcados pela construção Idade Média, portanto, há manifestações mais (muito 
mais!) ou menos ousadas quando se compara ao presente, em que o prefeito de uma grande cidade mobilizou agentes públicos para invadir um evento literário a fim de caçar livros 4 ... As cortes deram emprego a trovadores ousados, alguns deles eram os próprios príncipes. Trovadores que acusavam cavaleiros de sodomia diante dos mesmos para "recrear" a corte, não foram coagidos! E as cortes califais?! Tive o prazer de traduzir poemas de Abû Nuwâs, protegido de califas, que celebravam o vinho (lembremo-nos de que o vinho é interditado aos muçulmanos) e o homoerotismo.

(autor): O termo "medieval" foi também muito associado com o poder ilimitado das instituições religiosas ou com as crenças absolutas ou supersticiosas. Algumas pessoas, até de grande conhecimento acadêmico, quando veem as interferências das igrejas, sobretudo de alas neopentecostais, no Estado - ocupando cargos nas casas parlamentares e pressionando por suas pautas morais - afirmam que a "Idade Média foi instaurada no Brasil". Como era, de fato, a relação religiosa na Idade Média? Há também casos de maior tolerância e convivência pacífica entre credos diferentes?

M.L.G.: Ao longo de toda a Antiguidade Tardia (período que vai mais ou menos do século III ao VIII), a Igreja se viu mobilizada para a construção da sua ortodoxia, nos concílios ecumênicos. Ora, se a Igreja estava em dúvida e se debatia sobre a sua própria identidade teológica em meio a poderosos líderes políticos que se imiscuíam nos seus negócios, como afirmar seu poder de mando sobre todo mundo? Vamos acrescentar mais um fato: a autoridade imperial nesse contexto estava em Constantinopla, portanto o papa de Roma precisava negociar com o imperador bizantino e com poderosos patriarcas... Depois que o papa reconstruiu uma autoridade imperial no Ocidente, continuou a ter de negociar! Só a partir do século XI, a Igreja consegue propor de forma vigorosa uma argumentação e atrelá-la a ações que propuseram seu predomínio, ora, no século XI! Mas a Idade Média não acaba no XV?! Essas contas - de uma Idade Média subjugada na sua totalidade por uma igreja forte - estão um pouco desalinhadas... Isso, sem referir, com muito detalhe, o quanto essas argumentação e ações foram combatidas...

Sim, houve tolerância e convivência entre credos diferentes na Idade Média, mesmo em contexto de grande beligerância, como no período da Reconquista

${ }^{4}$ Refiro-me à invasão da Bienal do Rio, em setembro de 2019, a mando do prefeito Marcelo Crivella. 
na Península Ibérica. A vida de homens e mulheres foi sempre mais complexa e plural que nossos esquematismos.

(autor): Há notícias de como eram as Universidades no medievo? Presumo que seja algo bastante diferente do que, atualmente, vivemos no ambiente acadêmico. O que as instituições universitárias medievais nos legaram? Há o que aprender com elas?

M.L.G.: Esse é um dos temas que mais gosto de abordar. A Universidade tal qual a conhecemos nasceu na Idade Média! Temos de lembrar mais disso. A palavra designava uma corporação que unia mestres e alunos com intenção de ensinar e aprender. A transformação se deu quando essa reunião e esse ideal juntaram-se em instituição formal, protegida por reis, príncipes, imperadores e pelo papa, com ensino, titulação, biblioteca, colégios e com todo o "enxoval" que conhecemos hoje. As universidades tinham liberdades e direitos concedidos pelas autoridades que mencionei. Atenção à palavra que mencionei: liberdade. Na França, a Universidade de Paris brigou com a rainha Branca (1188-1252) e deflagrou greve. Luís IX (1214-1270), contrariando a sua mãe, fez as pazes com a instituição e ela voltou a funcionar.

(autor): A professora é também criadora do Blog Literistorias. Qual é o intuito das publicações do Blog?

M.L.G.: Literistorias é meu caderno de notas virtual. Compartilho com desconhecidos e conhecidos tudo aquilo que não cabe em meus artigos científicos e que me constitui também, como a minha literatura, minhas crônicas da vida acadêmica, traduções, resenhas de filmes e livros e outros textos que acho que ajudam meus alunos. Às vezes, eu me entrego à exploração de temas que congregam história pública e medievo. Recentemente fui motivada pela sugestão do presidente da República de reduzir as Normas Regulamentadoras em país campeão em acidentes de trabalho... O presidente chamou as normas atuais de "bizantinas" e ainda completou com os adjetivos "anacrônicas e hostis"5, então achei por bem escrever umas 2 ou 3 considerações a respeito.

5 Conferir: <http://literistorias.blogspot.com/2019/05/normas-bizantinas-e-outrasimprobidades.html $>$ 
Há séries muitos visitadas no blog, uma das mais é a série de resenhas. Também publico palestras, ou seja, produção técnica que não quero retocar para transformar em artigo, mas que desejo publicar com todas as suas marcas de tempo e oralidade. O blog tinha também uma ambição secreta: de me manter em constante exercício de escrita. Ele manteve essa ambição durante algum tempo (as atualizações eram semanais) até pelo menos eu ser eleita coordenadora do Programa de Pós-Graduação em História da UFPR. As exigências do cargo comprometeram o preenchimento do meu caderno. Mas eu acolho hoje de maneira mais equilibrada algumas necessidades que se me apresentam e acho que o blog pode esperar a coordenadora terminar o seu mandato.

(autor): É possível associar os acontecimentos passados com os do presente. Quais cuidados um historiador deve tomar para tecer tais análises sem cair no criticismo atemporal?

M.L.G.: Nos anos 90, o medievalista Georges Duby foi sabatinado por jornalistas que o convidaram a tecer algumas comparações entre os homens e as mulheres do ano 1000 e do ano 2000. O resultado disso é um livro muito bonito e totalmente acessível a um público de não especialistas ${ }^{6}$. Nessa obra que me ocorre como exemplo para responder-lhe, o grande Duby afirma que há semelhanças, afinal, continuamos a temer epidemias, a violência, a morte..., mas que é com as diferenças que aprendemos mais. Se há fatores que constrangem homens e mulheres ao longo da História, por exemplo, a fome, a doença, a relação com o meio ambiente, é preciso lembrar que as respostas são diversas, que elas são históricas, portanto. Outro dia disse em sala de aula que a História é para mim uma coleção de soluções de problemas no tempo. Eu quis produzir uma máxima de algum efeito sobre o que transcende qualquer tentativa de padronizar o devir. As sociedades respondem aos desafios propostos por elas mesmas, por suas inimigas ou pelo imponderável de forma diversa, pois respondem em condições também diversas.

A associação apressada ignora que nós estamos sempre em mudança e que, na aparência da mesmice, irrompem singularidades.

${ }^{6}$ DUBY, Georges. Ano 1000 ano 2000, na pista de nossos medos. São Paulo: Editora UNESP/Imprensa Oficial do Estado de São Paulo, 1999. 
(autor): Uma das medidas que está dando o que falar no Brasil é a insistência de Bolsonaro indicar o próprio filho, Eduardo, para a Embaixada dos EUA. O presidente do PSL, Luciano Bivar, afirmou que "A relação de embaixador é uma relação muito de confiança e apreço. Passando isso para a Idade Média, geralmente os reis entregavam suas filhas, seus filhos" e exemplificou com o caso do casamento de Catarina de Aragão (1485-1536) com o rei Henrique VIII (1491-1547) - embora o casamento não tenha acontecido propriamente no Medievo. O que a professora poderia comentar, à luz de seus estudos, acerca da justificativa do presidente do PSL?

M.L.G.: Eis um bom exemplo de uma associação infeliz. Portugal, França, Castela, Aragão... não eram países na Idade Média, mas reinos. Boa parte das soluções buscadas por homens e mulheres da época nesses reinos era construída a partir de vinculações pessoais. Em boa parte dessa longa temporalidade, ninguém entrava em uma guerra para defender um chão, imbuído de patriotismo, mas sim alguém, um senhor, por exemplo, a quem estava ligado por um conjunto de vínculos, volto a repetir, de natureza pessoal. Ao associar a intenção de um presidente eleito democraticamente para exercer um mandato de quatro anos em um Estado também democrático, com instituições e marcos regulatórios construídos na modernidade, ao medievo, esse senhor ignora que as condições são outras... e que o Brasil tem presidente que deve obedecer às leis do país, não tem rei, nem imperador. Aliás, não tem imperador há mais de um século.

(autor): Há seguidores e partidários de Bolsonaro que afirmam ser o presidente um "eleito de Deus", um "escolhido" pelo divino. O slogan de campanha utilizava a frase "Deus acima de todos". Da mesma maneira, o presidente se aproximou das alas mais conservadoras do neopentecostalismo evangélico e católico. Isso é descrito por muitos como algo relacionado ao medievo. O que você tem a dizer sobre a situação e a comparação de opositores?

M.L.G.: Os reis medievais eram pessoas duais, responsáveis pela justiça, fisco, mas também se achavam representantes de Deus na Terra. Estavam convencidos disso. Algumas moedas mandadas cunhar por D. João I (13571433), de Portugal, por exemplo, "tinham" poderes taumatúrgicos, para voltar ao cronista Fernão Lopes. A religião era importante a ponto de nenhum rei dormir tranquilo se estivesse excomungado... Mas novamente devo lembrar 
que as condições mudaram. O Brasil é um Estado Laico, portanto a reivindicação de Deus em campanhas políticas não tem a ver com o medievo embora pareça -, mas com uma intenção muito contemporânea de mobilizar um eleitorado sensível a tais associações no Estado Laico.

(autor): Falando em opositores: o presidente já deu mostras, mais de uma vez, de que, por ele, "varreria a oposição", o que é impensável em uma democracia consolidada. Em tempos da Idade Média também havia muitos jogos políticos. Havia, igualmente, a ideia de "varrer os opositores"?

M.L.G.: Sim. Muitos monarcas medievais desejaram coibir violentamente a oposição às suas práticas, outros mandaram matar seus opositores e ainda outros assassinaram pessoalmente inimigos. Isto tudo sem perder a coroa. Mas é equivocado afirmar que esses crimes eram realizados exclusivamente na Idade Média... Na Antiguidade, na Época Moderna e na Contemporaneidade, líderes políticos mandaram matar e mataram. Mas é preciso lembrar que, em diversos contextos, esse tipo de aniquilamento violento de qualquer possibilidade de diálogo e oposição era um crime.

(autor): $\mathrm{O}$ investigador está sempre preocupado em averiguar se os fatos aconteceram realmente da maneira em que se convencionou narrar. Contudo, parece haver, por partes de alas extremistas, um revisionismo nada positivo da História, negando o papel do intelectual e da Academia na sociedade e afirmando, por exemplo, a inexistência dos Campos de Concentração na Alemanha ou mesmo a presença colonizadora portuguesa em África. Na Era da Tecnologia, como é o papel do medievalista num país jovem como o Brasil? O que há para fazer?

M.L.G.: Um velho historiador muito importante no século XX, um homem de ação, que lutou em duas guerras, recebeu 4 medalhas, a Legião de Honra, e foi fuzilado pelos nazistas, chamado Marc Bloch, escreveu sobre a crítica história e a crítica ao testemunho. Em 1914, quando tinha 28 anos e não podia imaginar que a revista fundada por ele e por um grande amigo haveria de mudar os rumos do campo ${ }^{7}$, ele afirmou que as regras desse método não são um jogo de eruditos (BLOCH, 2019, p. 67). Isto significa que perguntar sobre a autenticidade da informação, sobre os interesses e circunstâncias em que ela foi

${ }^{7} \mathrm{~A}$ revista é a revista dos Annales, e o amigo é o historiador Lucien Febvre. 
consignada, sobre fraude e maledicência, não são tarefas exclusivas de historiadores... É dever de pessoa que deseja se manter bem-informada.

Um equívoco que se disseminou nos últimos tempos é achar que a História é uma opinião, quando a História é uma ciência, com procedimentos e métodos, e uma disciplina consolidada. As sociedades tiveram percepções muito diferentes sobre a História na diacronia, mas há muito tempo nem achamos mais que ela é mestra da vida (como na Antiguidade e na Idade Média), nem deixamos de reconhecer que ela congrega conhecimento relevante sobre a vida de homens e mulheres no tempo. Desacreditar a História hoje revela uma intenção determinada de apagamento. A serviço de quê? Da criação de narrativas intencionalmente comprometidas com projetos políticos que temem a ciência e a verdade.

Sobre o estudo da Idade Média no Brasil, dois aspectos: 1. Estudar temporalidades longas em uma jovem nação como a nossa é reconectar a nossa História a uma História mais longa que, entretanto, também nos constitui culturalmente, politicamente e socialmente; 2. medievalistas brasileiros não estão "constrangidos" por um passado diretamente identificado como nosso. Estamos mais isentos, portanto. Nossa contribuição é reconhecida e oferece vieses de compreensão mais livres: de eventos, ciclos, individualidades e problemas.

Há muito o que fazer no campo, e felizmente a tecnologia colabora conosco! Há um universo de fontes digitalizadas, aliás sou uma entusiasta da digitalização de documentos, procedimento que protege as fontes e democratiza o estudo. A digitalização e a publicação de boas edições nos permitem realizar um trabalho de qualidade no Brasil e participar de debates em pé de igualdade com nossos pares internacionais.

Em tempos de equívocos como os que vivemos, o estudo da História exige coragem, paciência e disciplina. É preciso refutar o desejo totalitário de tudo abarcar (sobretudo quem trabalha com as lacunares fontes antigas e medievais...) e trazer para a divulgação do resultado da pesquisa os procedimentos de cada etapa, como fazem excelentes historiadores que não temem compartilhar com os leitores os seus limites. Afinal, a ilusão de unidade e o firme desejo de aplanar as contradições servem mais às narrativas comprometidas que à verdade a que aspiramos cientificamente. 


\section{Referências}

AMALVI, Christian.

(2006). Idade Média. In: LE GOFF, Jacques; SCHMITT, Jean-Claude (orgs.). Dicionário temático do Ocidente Medieval. Bauru: EDUSC, vol. 1, p. 537-551.

BLOCH, Marc.

(2019). Crítica histórica e crítica de testemunho. In: BENTIVOGLIO, Julio; OLIVEIRA, Josemar Machado de (orgs.). Que pedir aos historiadores? Vitória: Editora Milfontes.

DUBY, Georges.

(1999). Ano 1000 ano 2000, na pista de nossos medos. São Paulo: Editora UNESP/Imprensa Oficial do Estado de São Paulo.

GUIMARÃES, Marcella Lopes.

(2019). Normas Bizantinas e outras improbidades. Disponivel em: <http://iteristorias.blogspot.com/2019/05/ normas-bizantinas-e-outrasimprobidades.html>. Acesso em: 8 set. 2019.
MENDES, Eduardo Soczek.

(2017). Alexandre Herculano, entre o Presbitero $e$ o Monge: o (anti)clericalismo e as personagens religiosas em Monasticon (Eurico, o presbítero e 0 Monge de Cistér). Dissertação de Mestrado (em Letras), Universidade Federal do Paraná, Curitiba.

\section{Recebido em}

novembro de 2019

\section{Aprovado em}

março de 2021 